\title{
The impact of surgery and mild hyperthermia on tumor response and angioneogenesis of malignant melanoma in a rat perfusion model
}

\author{
Joerg Pelz*1, Marco Mollwitz ${ }^{1}$, Christian Stremmel ${ }^{1}$, Jonas Goehl1, \\ Arno Dimmler ${ }^{2}$, Werner Hohenberger ${ }^{1}$ and Thomas Meyer ${ }^{1}$
}

\author{
Address: ${ }^{1}$ Department of Surgery, University of Erlangen-Nuremberg, Germany and ${ }^{2}$ Institute of Pathology, University of Erlangen-Nuremberg, \\ Germany \\ Email: Joerg Pelz* - joerg.pelz@chir.imed.uni-erlangen.de; Marco Mollwitz - marco.mollwitz@web.de; \\ Christian Stremmel - christian.stremmel@rzmail.uni-erlangen.de; Jonas Goehl - jonas.goehl@chir.imed.uni-erlangen.de; \\ Arno Dimmler - Arno.Dimmler@patho.imed.uni-erlangen.de; Werner Hohenberger - werner.hohenberger@chir.imed.uni-erlangen.de; \\ Thomas Meyer - thomas.meyer@chir.imed.uni-erlangen.de \\ * Corresponding author
}

Published: 23 August 2004

BMC Cancer 2004, 4:53 doi:10.1/86/147/-2407-4-53

This article is available from: http://www.biomedcentral.com/I47|-2407/4/53

(C) 2004 Pelz et al; licensee BioMed Central Ltd.

This is an open-access article distributed under the terms of the Creative Commons Attribution License (http://creativecommons.org/licenses/by/2.0), which permits unrestricted use, distribution, and reproduction in any medium, provided the original work is properly cited.

\begin{abstract}
Background: The aim of this experimental study was to determine the effect of mild hyperthermia on tumor response and angioneogenesis in an isolated limb perfusion model with a human melanoma xenograft.

Methods: A human melanoma xenograft was implanted into the hindlimbs of 30 athymic nude rats. The animals were randomized into five groups: group I: control, group II: sham group, group III: external hyperthermia with a tissue temperature of $41.5^{\circ} \mathrm{C}$ for 30 minutes without ILP, group IV: normothermic ILP (tissue temperature $37^{\circ} \mathrm{C}$ for 30 minutes, group V: hyperthermic ILP (tissue temperature $41.5^{\circ} \mathrm{C}$ for 30 minutes). Tumor response was evaluated by tumor size determination and immunohistochemical analysis 6 weeks postoperatively. Tissue sections were investigated for expression of CD34 and basic fibroblast growth factor (bFGF).
\end{abstract}

Results: Average tumor volumes of the controls (I) increased from $105 \mathrm{~mm}^{3}$ to $1388 \mathrm{~mm}^{3}$. In the sham operated group (II) tumor volumes were significantly larger than in group I. Tumor volumes in group IV were significantly smaller than in group I and lowest in group V. There were no significant differences in size between group I and group III after six weeks. In group III and IV each, 5 animals showed tumor progression and one had a partial tumor response. In group $V$ only 2 animals showed tumor progression. Immunhistochemical analysis of the tissue sections demonstrated that angioneogenesis was more pronounced in group II than in group I and less pronounced in group IV and V compared with group I.

Conclusions: Our results suggest that even a surgical manipulation such as a skin incision promotes tumor growth, probably by induction of growth factors like bFGF.

External hyperthermia of $41.5^{\circ} \mathrm{C}$ tissue temperature for 30 minutes only has no impact on tumor growth and angioneogenesis in vivo. 


\section{Background}

Hyperthermic isolated limb perfusion is an established treatment for multiple, locoregional intransit metastases of malignant melanoma and soft tissue sarcomas of the extremities. It was introduced 1957 by Creech and Krementz [1]. The procedure allows a high locoregional concentration of cytostatics with few systemic side effects [2]. Isolated limb perfusion achieves local tumor control in a high percentage of cases. Complication rate of perfusion is acceptably low. A surviving model for isolated perfused rat hindlimbs was reported by Wu et al. [3] based on the perfusion model of Nagel et al.[4].

Angioneogenesis has been recognized for many years to play a central role in the growth of primary tumors and the formation of metastases in general $[5,6]$. Melanomas express basic fibroblast growth factor (bFGF) and fibroblast growth factor receptor-1 (FGFR-1) in their dermal nevocytes and in the stroma. bFGF promotes angiogenesis in vivo [7] and in vitro [8]. Antisense targeting of bFGF/ FGFR-1 in malignant melanomas blocks intratumoral angioneogenesis [9].

Hyperthermia inhibits angioneogenesis. Some of the antineoplastic effects of hyperthermia are caused by ischemia due to obstruction or destruction of the tumor vessels. Eikesdal et al. described by hyperthermic temperatures disrupture of $25-50 \%$ of the vasculature in malignant tumors. The heated tumors $\left(44^{\circ} \mathrm{C}\right)$ had a blood flow reduction of $40-60 \%$ after 24 hours [10].

In vitro data indicate that capillary endothelials cells of malignant neoplasms are more thermosensitive than endothelial cells of normal tissues. The vascularization of tumors can be significantly damaged at temperatures which may alter but do not damage the vasculature of normal tissue [11]. The extent of the proliferation of vessels is also inversely related to temperature [12]. The critical temperature at which a direct vascular damage occurs is between 42.7 and 43.7 degrees C [13].

Hyperthermia increases the effects of angioneogenesis inhibitors on tumor growth and tumor angioneogenesis [14]. The aim of this experimental study was to determine the impact of hyperthermia on tumor response and angioneogenesis in an isolated limb perfusion model.

\section{Methods}

Thirty inbred male nude athymic rats (Rowett $\mathrm{rnu} / \mathrm{rnu}$ ) weighting 200 to $280 \mathrm{~g}$ were used in this study. Animals were kept separately during the experiment with 12 hours of light per day. They were fed a standard laboratory diet and tap water ad libidum. Maintenance and care of all experimental animals were carried out according to the guidelines of the local responsible Animal Protection
Commission and carried out in compliance with national guidelines (National Institute of Health for Use of Laboratory Animals).

A solid sample $(2 \times 2 \times 2 \mathrm{~mm})$ of a human melanoma xenograft (SK-MEL-3), derived from a lymph node melanoma metastasis, was implanted into the hindlimbs of 30 nude rats. The largest width and the maximum tumor diameter perpendicular to the width were measured with a micrometer. Only tumors with a diameter greater than $>12 \mathrm{~mm}$ in the largest diameter were included in the study.

The details of the perfusion system have been described previously [4]. The equipment consisted of a miniature oxygenator, a heat exchanger and a roller pump. Venous blood of the limb was oxygenated in the oxygenator $\left(99.15 \% \mathrm{O}_{2} ; 0.85 \% \mathrm{CO}_{2}\right)$ and warmed in the heat exchanger. The warmed arterialized perfusate is driven by a roller pump with two synchronously running pumpheads on a single axis for the arterial and venous lines $\left(\right.$ Masterflex $\left.^{\circledast}\right)$. The outer diameters of the tubes corresponded with the diameter of the femoral vessels of nude rats weighting about $250 \mathrm{~g}$ (arterial $0.7 \mathrm{~mm}$; venous 1.0 $\mathrm{mm})$.

Rat hindlimbs were perfused with ringer's solution and sodium heparin (25 IU/100 $\mu \mathrm{l}$ saline) at 37 or 41.5 degrees $\mathrm{C}$ for 30 minutes with a flow rate of $4 \mathrm{ml} / \mathrm{min}$. External hyperthermia was applied by an infrared lamp positioned in a fixed distance to the tumor.

For temperature measurement during limb perfusion, a nickel-chrom-nickel thermocouple of $0.6 \mathrm{~mm}$ in diameter (Standard Integrated Thermocouple Thermocoax, Phillips, Hamburg, Germany) was placed at the macroscopic tumor margin. The thermocouple was calibrated before use in a high-precision water bath. Baseline temperature was recorded for 5 minutes before treatment. Temperature was continuously measured during application. In group I (control) and group II (sham operated) temperature measurement was not performed.

The animals were randomized into a control and four study groups of six animals each: group I: control (no therapy), group II: sham group (skin incision without ILP), group III: external hyperthermia with a tissue temperature of $41.5^{\circ} \mathrm{C}$ for 30 minutes without ILP, group IV: normothermic ILP (Ringer's solution as perfusate, tissue temperature $37^{\circ} \mathrm{C}$ for 30 minutes, group V: hyperthermic ILP (tissue temperature $41.5^{\circ} \mathrm{C}$ for 30 minutes). ILP was subsequently performed with the above-mentioned parameters. Antineoplastic agents were not applied. 


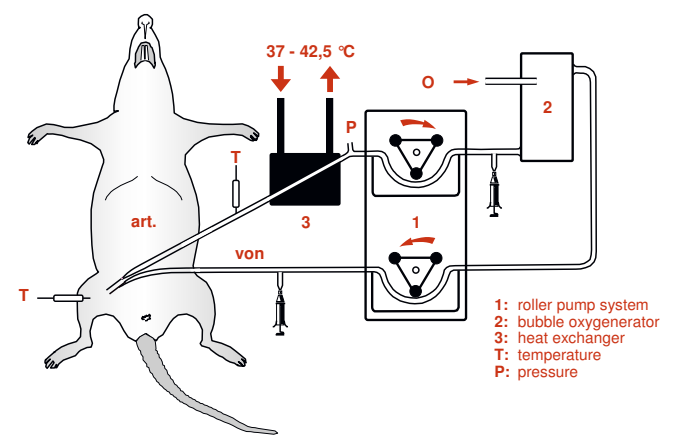

\section{Figure I}

Diagrammatic outline of the experimental setup. I: roller pump system; 2: bubble oxygenerator; 3: heat exchanger, T: temperature

The rats were anaesthetized with Ketamin (Ketanest ${ }^{\circledast}, 80$ $\mathrm{mg} / \mathrm{kg}$ i.m.; Pearl-Davis, Berlin, Germany) and Xylazin (Rompun ${ }^{\circledast}, 10$ mg/kg i.m.; Bayer, Leverkusen, Germany), and fixed in a supine position. For perfusion, the animals underwent a $3-\mathrm{cm}$ incision of the groin. The left femoral artery and vein were isolated using an operation microscope. A vascular clip was placed across the artery and a silicon catheter (outer diameter $0.7 \mathrm{~mm}$ ) was introduced via a transverse arteriotomy. The femoral vein was cannulated with a silicon catheter of $1 \mathrm{~mm}$ outer diameter (Fig. 1). Tourniquets were applied around the left hindlimb to ensure isolation. Rat hindlimbs were perfused at a flow rate of $4 \mathrm{ml} / \mathrm{h}$, for $30 \mathrm{~min}$. After treatment, the silicon catheters were removed, and the vein and the artery were sutured (8/0 Prolene), to restitute normal blood flow. After the isolated limb perfusion the wound was closed in two layers. Total operation time rated about $90 \mathrm{~min}$.

During the first 5 days after operation the rats were weighed daily, and once a week there-after. The animals were kept under standardized conditions and were killed by an overdose of anesthetic and cervical dislocation 6 weeks after treatment. The greatest tumor width and the maximum diameter perpendicular to the width were macroscopically measured with a micrometer. Lesion volume was calculated using the formula $\mathrm{v}=4 \times \pi \times \mathrm{a} \times \mathrm{b} 2 / 3$, in which $\mathrm{a}$ and $\mathrm{b}$ are the radii of the measured axes. The tumor was then completely sectioned. Each tumor was divided into two parts. One part was fixed in 4 per cent formalin solution for 5 days, embedded in paraffin and stained with hematoxylin and eosin (H\&E). The other part was fixed in $0.9 \%$ saline solution, frozen and stored at $-80^{\circ} \mathrm{C}$ until use.

Vascular density and tumor morphology were evaluated by immunohistochemistry. Tumor tissue was tested for expression of basic fibroblast growth factor (bFGF) and CD34.

Tissue specimens were fixed in $10 \%$ formaldehyde and embedded in paraffin according to routine protocols. Sections $4 \mu \mathrm{m}$ thick were deparaffinized and rehydrated using graded ethanols following routine protocols. For antigen retrieval all sections were microwave treated for 20 minutes in target retrieval solution (for bFGF; DAKO, Glostrup, Denmark) or $10 \mathrm{mM}$ citrate buffer (for CD34) at $700 \mathrm{~W}$. The sections were incubated overnight with primary mouse anti-bFGF (1:50; Becton Dickinson, Heidelberg, Germany) and anti-CD34 antibody (1:100; Immunotech, Hamburg, Germany). After rinsing in Tris buffer detection was carried out with a biotinylated secondary rabbit anti-mouse antibody diluted 1:50 (DAKO, Glostrup, Denmark) for 30 minutes at room temperature. The sections were washed again as above in Tris buffer and then incubated with streptavidin-biotin-alkaline-phosphatase $(10 \mu \mathrm{l}$ each solution A+B (Sigma, Deisenhofen, Germany) in $10 \mathrm{ml}$ Tris). Immunohistochemical staining was visualized with Fast Red (2 mg Naphtol-As-Mx-phosphate, $10 \mu \mathrm{l} 1 \mathrm{M}$ Levamisol and $10 \mathrm{mg}$ Fast-Red (Sigma) in $0.2 \mathrm{ml} \mathrm{N}, \mathrm{N}$-dimethylformamide, (Merck, Darmstadt, Germany) and $9.8 \mathrm{ml} \mathrm{0.1} \mathrm{M} \mathrm{Tris-HCl} \mathrm{buffer} \mathrm{at} \mathrm{pH8.6).}$ The sections were rinsed in $\mathrm{H}_{2} \mathrm{O}$ and counterstained with hemalaun. Negative controls without primary antibody were run for each sample.

Tumor response was graded according to the system described by de Wilt et al. [15]. Progressive disease (PD) was defined as a tumor size $>125 \%$ of the size at the time of treatment, in tumor sizes of $100 \pm 25 \%$ no change (NC) was stated. Response was graded as partial (PR) if tumor sizes was between 10 and $75 \%$ and complete (CR) for tumor size $<10 \%$ of its original diameter.

In areas of intense neovascularized spots microvessels were counted in a $100 \times$ field. A microvessel was defined as a lumen surrounded by a rim of endothelial cells highlighted by immunostaining with anti-CD34 antibodys or anti-bFGF antibodys. Five separate intense neovascularized areas were assessed, and the mean was calculated as microvessel density of each tumor. The score was assessed by two independent observers.

Data were analyzed using SPSS/PC+ statistical software. The mean and range of tumor and lesion volumes were calculated for each group. For comparison of tumor volume and microvessel density between the diffent groups a 
non-parametric test was used (Kruskal-Wallis). A p value $<0.05$ was considered to be significant.

\section{Results}

During intervention, the required limb tissue temperature was reached within 8-12 minutes in group IV and 10-15 minutes in group III. Stable temperatures were then maintained for a further 30 minutes with a mean of $41.4^{\circ} \mathrm{C} \pm$ 0.5 . To reach limb tissue temperature the perfusion fluid maintained $43^{\circ} \mathrm{C} \pm 0.4$.

\section{Tumor and lesion Volumes}

Before treatment, the mean (s.e.m) volume of the treated tumors in groups I, II, III, IV and V was $105 \mathrm{~mm}^{3}$ (4.3), 98 $\mathrm{mm}^{3}$ (5.7), $108 \mathrm{~mm}^{3}$ (3.4), $95 \mathrm{~mm}^{3}$ (5.0) and 107 (4.1) $\mathrm{mm}^{3}$ respectively, with no significant difference between the groups. Average tumor volume of the controls (I) increased to $1388 \mathrm{~mm}^{3}$ (101) during six weeks. In the sham operated group (II) tumor volume was significantly larger than in group I $\left(2350 \mathrm{~mm}^{3}(198.6), P=0.021\right)$. Tumor volume in group IV was significantly smaller $\left(1009 \mathrm{~mm}^{3}(122.5)\right)$ than in group I and lowest in group V $405 \mathrm{~mm}^{3}$ (103.6) $(P=0.036$ and $P=0.021$, respectively.). There were no significant differences in size between group I and group III (1135 $\mathrm{mm}^{3}$ (99)) after six weeks $(P>0.05)$ (Fig. 2).

\section{Body weight}

After the perfusion, body weight decreased in all groups during the first 5 days with a maximum of $8 \%$. In the following weeks, body weight mounted up to $130 \%$ of the preoperative value. In the last week of the experiment, the weight almost reached a plateau. No significant differences between the five experimental groups were found.

\section{Histology}

In the H\&E staining the untreated melanoma (group I) presented as a subcutanous unilocular nodule of moderate differentiation. The tumor showed mainly tubular structures with vacuole like lumen formation and was infiltrated with fibrous septa. The spontaneous rate of necrosis was estimated to be $20 \%$. Numerous mitoses were detected. Tumor morphology did not change with ageing or tumor size. Histology was similar in group II.

In group $\mathrm{V}$ the tumors showed signs of irreversible cell damage after treatment. Tumor cells displayed clear shrinkage and partial loss of cell contact. Thromboses of the larger adjacent vessels were found on the tumor-skin border. Macrophage infiltration was present in all groups, but was more numerous pronounced in group $\mathrm{V}$. In group III and IV there were less signs of irreversible cell damage after treatment than in group $\mathrm{V}$.

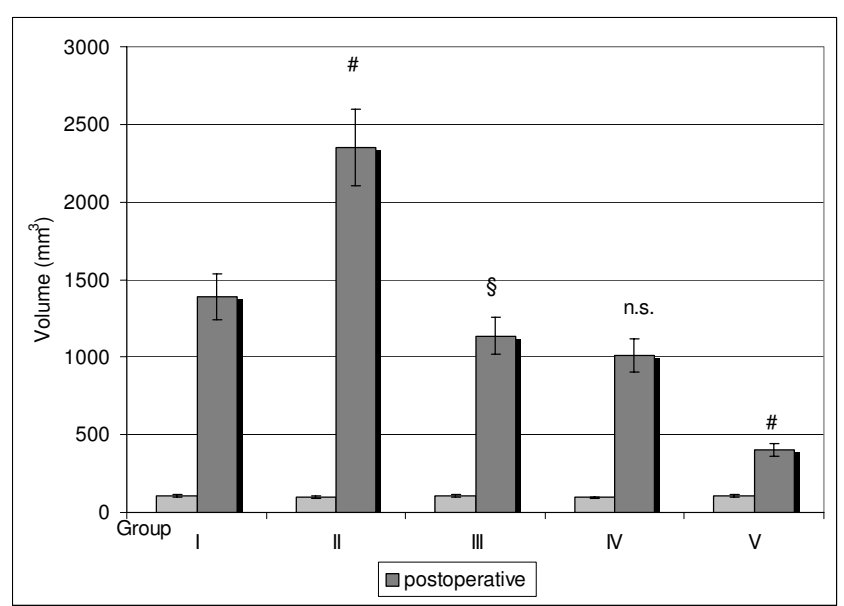

\section{Figure 2}

The mean tumor volumes + SEM of groups I to $V(n=30) 6$ weeks after treatment; Group II, III, IV and V compared to group I ( $\$: P=0.036 ; \#: P=0.02$ I (Kruskall-Wallis) n.s.:not significant).

Immunhistochemical analysis of the histological sections for bFGF demonstrated that microvessel density of group I (Fig 3) ranged from 18 to 23 with a mean value of 20. Angioneogenesis was more pronounced in group II (Fig $4)$ than in group I $(p=0.003)$ and less pronounced in group IV and V (Fig 5) compared with group I ( $\mathrm{p}=0.023$, $\mathrm{p}=0.001)$. There were no significant differences in the expression of angiogenetic markers between group I and group III $(\mathrm{p}>0.05)$.

Immunhistochemical analysis of the histological sections for CD34 showed that microvessel density of group I ranged from 17 to 23 with a mean value of 19 . Angioneogenesis was more pronounced in group II than in group I $(\mathrm{p}=0,001)$ and less pronounced in group IV and V compared with group I $(\mathrm{p}=0.023, \mathrm{p}=0.017)$. There were no significant differences in the expression of angiogenetic markers between group I and group III ( $p>0.05)$.

Strong expression of bFGF and CD34 was found in the cytoplasm of intimal endothelial and medial smooth muscle cells. Expression of bFGF and CD34 was stronger at the invasion front than in the centre of tumors.

Summarized data of the expression intensity of bFGF and CD34 in the tumors are given in table 1.

\section{Tumor remission}

In group I and II tumor progression was observed in all animals macro- and microscopically. In group III and IV 5 animals showed tumor progression and one had a partial 


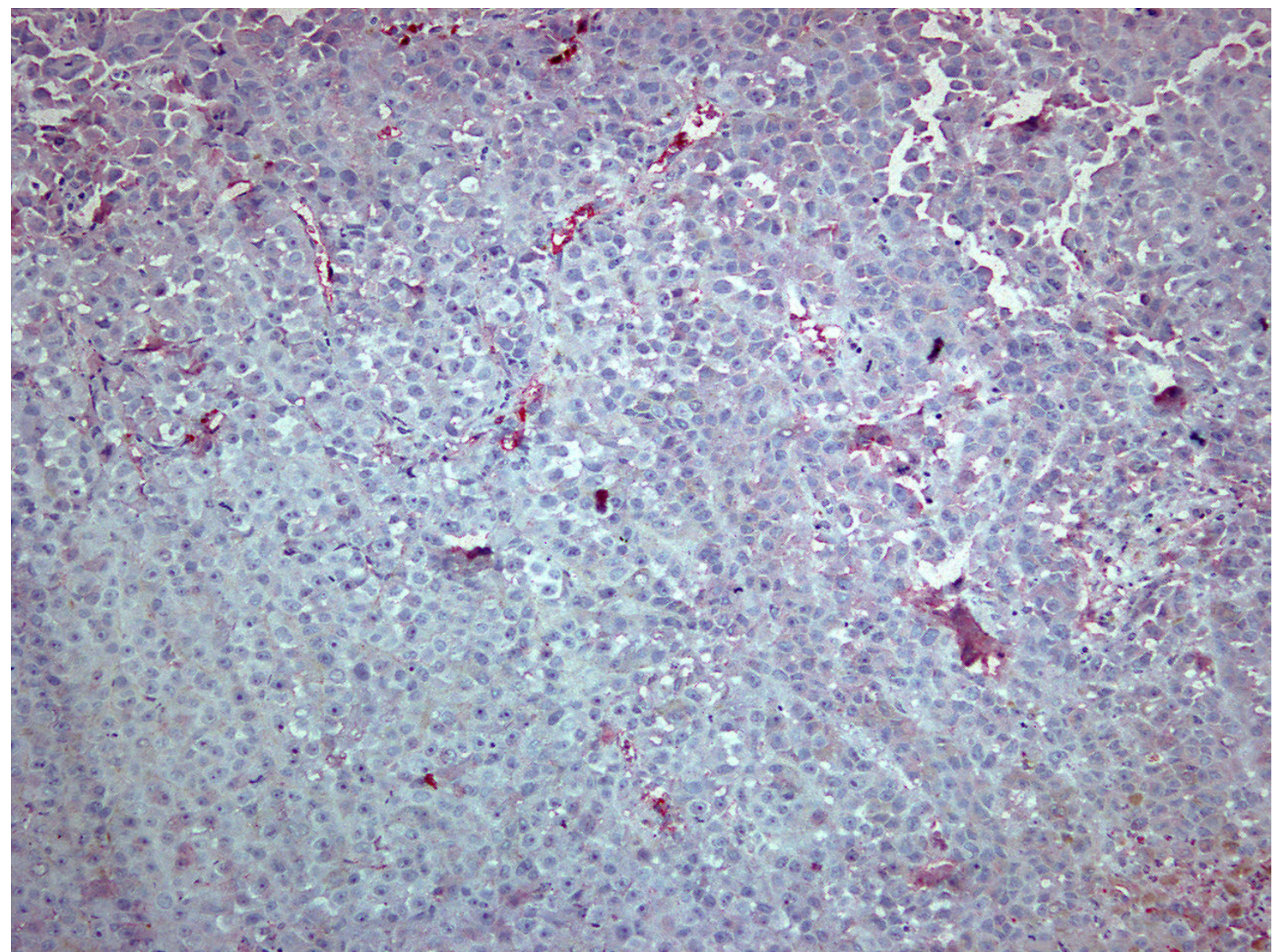

Figure 3

Immunohistochemical staining for bFGF in group I (control): Microvessels are represented by red clusters, which stand out sharply from other tissues.

tumor response. In group $\mathrm{V}, 2$ animals showed tumor progression, 2 had a complete remission. One had a partial tumor response and one had no change in tumor response (table 2).

\section{Discussion}

A phenomenon that has been described by numerous authors is the rapid increase of tumor growth following surgical manipulation $[16,17]$.

This was also observed in our sham-operated group of animals (group II) in which tumors grew more rapidly than in the control group (group I). This implies that resection is associated with an accelerated growth in residual tumors. It is assumed that the surgical manipulation induces liberation of growth factors that in addition to their effect on healing also have a stimulating effect on tumor proliferation.

This hypothesis is supported by the results of our immunohistochemical investigations, which revealed an enhanced expression of fibroblast growth factor (bFGF) in group II. In an intraperitoneal tumor model, EGGERMONT et al. showed that the surgical intervention of laparotomy induces an increase of carcinomatosis in the entire peritoneal cavity. At the same time, the immunotherapeutic effect of interleukin 2 and natural killer cells is significantly reduced. It must therefore be speculated that surgical trauma induces a temporary immunosuppressive effect that influences tumor growth $[16,18,19]$. 


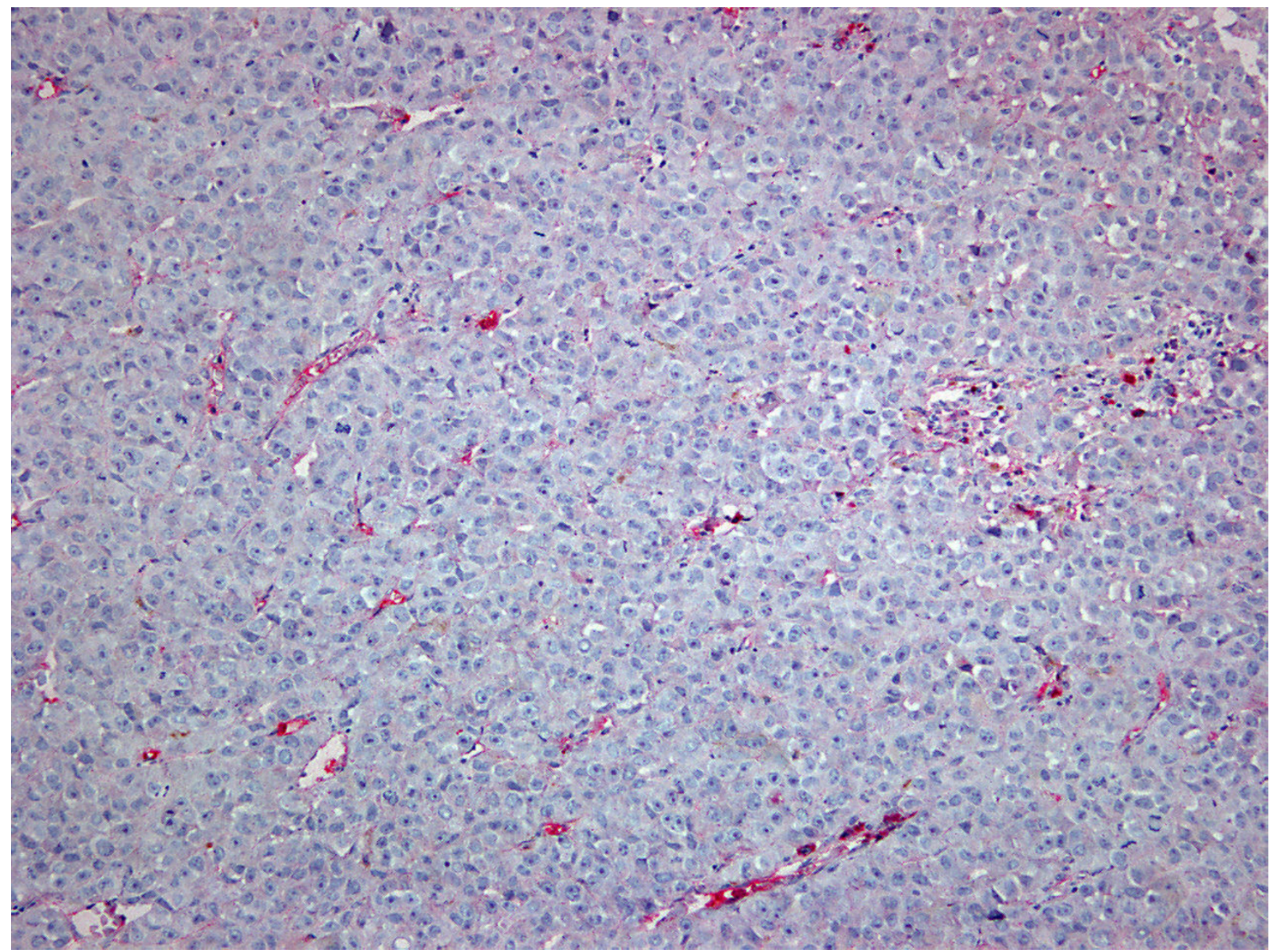

\section{Figure 4}

Immunohistochemical staining for bFGF in group II (sham operated): More microvessels are represented in the margin of the tumor.

In our experiments, group V (hyperthermic perfusion) showed a significant slowing of tumor growth in comparison with the control group. This was also confirmed by the immunohistochemical investigations that showed a reduction in the expression of relevant markers of the vascular endothelium. Indeed, two of the six animals occurred a complete remission of their tumor. The observation that two animals in this group experienced tumor progression can probably be explained by the duration of the intervention, since factors affecting the kinetics of cell death during hyperthermia are not only the maximum temperature induced, but also the duration of the elevated temperature.
In an overview report BHUYAN noted that, as a function of various tumor cell types, a temperature of $43^{\circ} \mathrm{C}$ must be applied between 30 and 150 minutes to irreversibly damage the tumor cells. At a temperature of $45^{\circ} \mathrm{C}$, the application time required varied between 13 and 85 minutes [20]. In our experiments, the application time was only 30 minutes at a temperature of $41.5^{\circ} \mathrm{C}$. Nevertheless, the relatively short application time also had an appreciable damaging effect on the metastatic vessels.

Although the temperature in group III (external hyperthermia) was also $41.5^{\circ} \mathrm{C}$ applied for 30 minutes, no significant changes in the growth pattern of the tumor could 


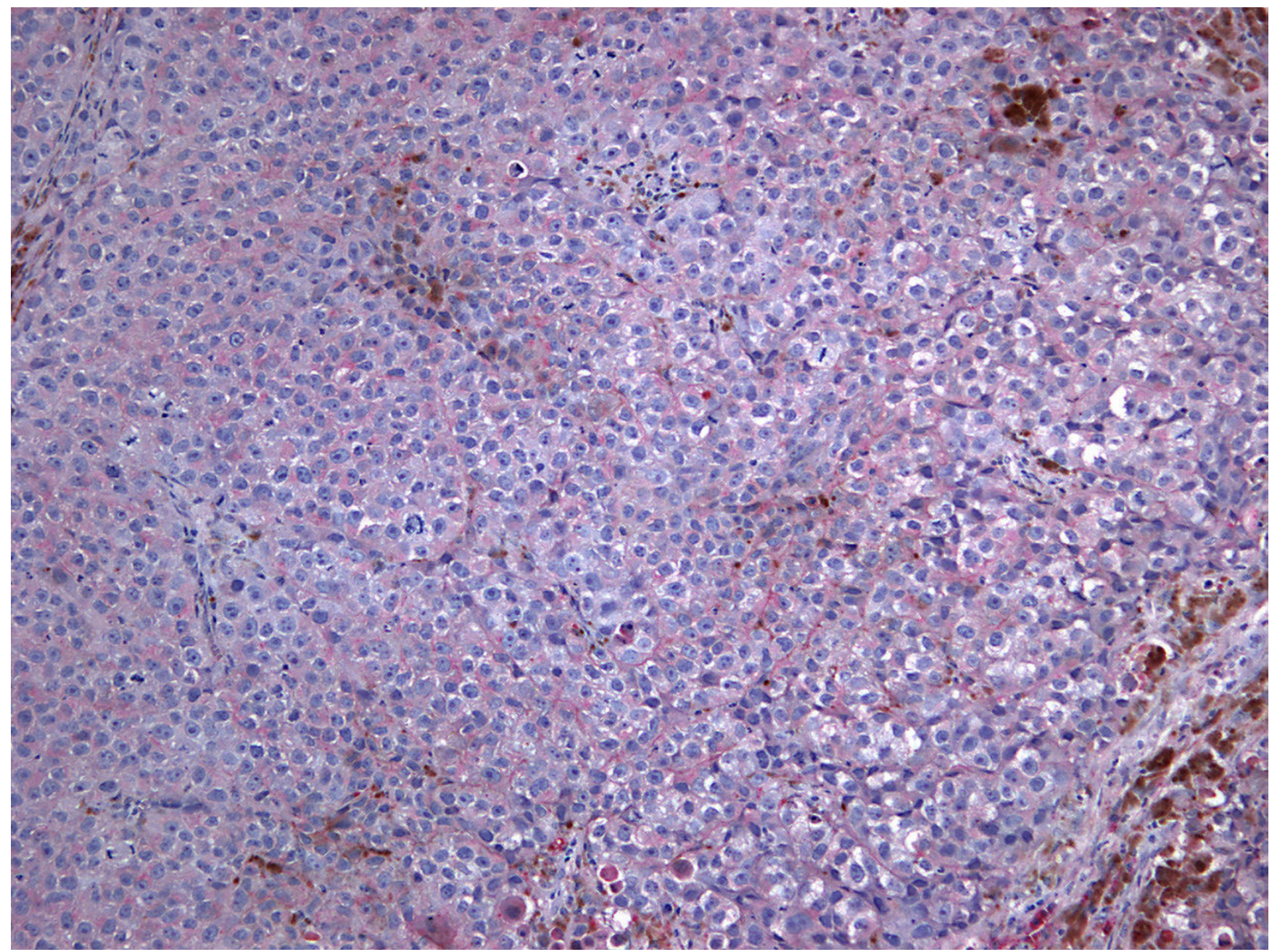

\section{Figure 5}

Immunohistochemical staining for bFGF in group V (HILP): Angioneogenesis is less pronounced as in group I. Brown clusters represent melanin.

be observed. Furthermore, the histological and immunohistochemical evaluations showed a mild hyperthermic damage at best. A comparison of treatment groups III and $\mathrm{V}$ revealed no differences in terms of duration of treatment and induced tissue temperatures.

In contrast to group III, however, hyperthermia in group $\mathrm{V}$ has been mediated directly by the vascular system. In normal tissues subjected to warming, blood perfusion increases reactively via dilatation of the vessels together with an increase in vessel wall permeability. A decisive factor is that the tumor cells themselves, as well as the endothelial cells of tumor vessels are more thermosensitive than normal tissue $[16,21,22]$. Other authors have also shown that hyperthermia is capable of destroying vascular architecture, so that perfusion of the tumor is reduced. The sensitivity of various tumors, however, varies considerably [14]. ILP and other vasculotoxic effects like TNFalpha in combination with melphalan or doxorubicin increase the uptake of these drugs of three to six times [23].

Heat transfer between the vascular system and the tissue is determined in particular by the nature of the blood vessels. Important factors are the number, length, and diameter of the vessels, and also the velocity of blood flow [24]. CREZEE described the relationship between tumor perfusion and heating of the tumor tissue under systemic hyperthermia. He could show that the induction of heat in the tumor depends on the density of the blood vessels within the tumor itself. The more vessels in the tumor exist, the easier it is to heat the lesion via the vascular system. Heattransfer is particularly pronounced with largecalibre blood vessels or high flow velocity, and its rate is 
Table I: Summarized data of the expression intensity of bFGF and CD34

\begin{tabular}{lcccc}
\hline & CD34 & P to group I & bFGF & P to group I \\
\hline group I & 19 & --- & 20 & 0.003 \\
group II & 28 & 0.001 & 26 & $>0.05$ \\
group III & 20 & $>0.05$ & 21 & 0.023 \\
group IV & 27 & 0.023 & 26 & 0.001 \\
group V & 16 & 0.017 & 16 & \\
\hline
\end{tabular}

Table 2: Tumor response to treatment of isolated limb perfusion. Tumor diameters were measured and expressed as a percentage of the size at the time of treatment.

\begin{tabular}{cccccc}
\hline response & group I & group II & group III & group IV & group V \\
\hline complete & $0 / 6$ & $0 / 6$ & $0 / 6$ & $0 / 6$ & $2 / 6$ \\
partial & $0 / 6$ & $0 / 6$ & $1 / 6$ & $1 / 6$ & $1 / 6$ \\
no change & $0 / 6$ & $0 / 6$ & $0 / 6$ & $0 / 6$ & $1 / 6$ \\
progressive & $6 / 6$ & $6 / 6$ & $5 / 6$ & $5 / 6$ & $2 / 6$ \\
\hline
\end{tabular}

all the greater the higher the temperature gradient between the tumor tissue and the blood $[25,26]$.

On the other hand, tumor vasculature carries away the externally applied heat (group III) which is then no longer available to destroy the tumor cells. In this case, the temperature gradient decreases from the tumor to the vascular system.

Furthermore, in the presence of hyperthermia, microcirculation in the tumor tissue is more affected than in normal tissue [27]. In addition, manipulation to the vascular system, and thus oxygenation of the tumor, also appears to play an important role. Although the body's own oxygenated blood is added to the perfusate, the dilution effect together with the clamping time, leads to a relative reduction in perfusion. It is known that hypoxia, in conjunction with a decrease in the $\mathrm{pH}$ and energy status of the cell, enhances thermosensitivity [28-30], and this increase correlates with the size of the tumor [31].

Our results have also confirmed that surgical manipulation of the vascular system and perfusion have an influence on the tumor. Overall, the effect of the intravascular application of hyperthermia appears to be mediated by a combination of hypoxia and heat.

\section{Conclusions}

Our results suggest that even a surgical manipulation such as a skin incision promotes tumor growth, probably by induction of growth factors like bFGF. External hyperther- mia of $41.5^{\circ} \mathrm{C}$ tissue temperature for 30 minutes has no impact on tumor growth and angioneogenesis in vivo. Hyperthermic isolated limb perfusion effectively suppresses tumor angioneogenesis respectively tumor growth.

\section{Competing interests}

None declared.

\section{Authors' contributions}

JP carried out the treatment and drafted the manuscript.

MM carried out the treatment.

CS carried out the immunohistochemical studies.

JG participated in the design of the study.

AD carried out the histological studies.

WH participiated in the design of the study.

TM participiated in the design and coordination of the study.

All authors read and approved the final manuscript.

\section{Acknowledgements}

This study was supported by grants from ELAN (Erlanger Leistungsbezogene Anschubfinanzierung und Leistungsförderung). 


\section{References}

I. Creech OJ jr, Krementz ET, Ryan RF, Winblad JN: Chemotherapy of cancer: Regional perfusion utilizing an extracorporal circuit. Ann Surg 1958, I48:616-632.

2. Hohenberger W, Meyer T, Gohl J: Extremity perfusion in malignant melanoma. Chirurg 1994, 65:175-85

3. Wu Z, Roberts MS, Parsons PG, Smithers BM: Isolated limb perfusion with melphalan for human melanoma xenografts in the hindlimb of nude rats: a surviving animal model. Melanoma Res 1997, 7:19-26.

4. Nagel K, Ghussen F, Krüger I, Isselhard W: Miniature Equipment for the perfusion of rat limbs. Res Exp Med 1987, 187: I-8.

5. Folkman J: Tumor angiogensis: role in regulation of tumor growth. Symp Soc Dev Biol 1974, 30:43-52.

6. Folkman J: Tumor angiogenesis: a possible control point in tumor growth. Ann Intern Med 1975, 82:96-100.

7. Shih IM, Herlyn M: Autocrine and paracrine roles for growth factors in melanoma. In Vivo 1994, 8: I I3-23.

8. Montesano R, Kumar S, Orci L, Pepper MS: Synergistic effect of hyaluronan oligosaccharides and vascular endothelial growth factor on angiogenesis in vitro. Lab Invest 1996 75:249-62.

9. Wang Y, Becker D: Antisense targeting of basic fibroblast growth factor and fibroblast growth factor receptor-I in human melanomas blocks intratumoral angiogenesis and tumor growth. Nat Med 1997, 3:887-93.

10. Eikesdal HP, Bjorkhaug ST, Dahl O: Hyperthermia exhibits antivascular activity in the s.c. BT4An rat glioma: lack of interaction with the angiogenesis inhibitor batimastat. Int Hyperthermia 2002, I 8: |4|-52.

I I. Song WJ, Weinbaum S, Jiji LM, Lemons D: A combined macro and microvascular model for whole limb heat transfer. J Biomech Eng 1988, I | 0:259-68.

12. Fajardo LF, Prionas SD, Kowalski J, Kwan HH: Hyperthermia inhibits angiogenesis. Radiat Res 1988, I | 4:297-306.

13. Nishimura $Y$, Hiraoka M, Jo S, Akuta K, Yukawa $Y$, Shibamoto $Y$, Takahashi $M$, Abe $M$ : Microangiographic and histologic analysis of the effects of hyperthermia on murine tumor vasculature. Int J Radiat Oncol Biol Phys 1988, I 5:4 I I-20.

14. Nishimura $Y$, Murata R, Hiraoka M: Combined effects of an angiogenesis inhibitor (TNP-470) and hyperthermia. $\mathrm{Br} J$ Cancer 1996, 73:270-4

15. De Wilt JH, Manusama ER, van Tiel ST, van ljken MG, ten Hagen TL, Eggermont AM: Prerequisites for effective isolated limb perfusion using tumor necrosis factor alpha and melphalan in rats. $\mathrm{Br} J$ Cancer 1999, 80:16I-166.

16. Eggermont AMM, Steller EP, Sugerbaker PH: Laparotomy enhances intraperitoneal tumor growth and abrogates the antitumor effectsinterleukin-2 and lymphokine-actvated killer cells. Surgery 1987, 102:7I-78.

17. Weese JL, Ottery FD, Emoto SE: Do operations facilitate tumor growth? An experimental model in rats. Surgery 1986 I 00:273-277.

18. Pollock RE, Lotzova E, Stanford SD: Surgical stress impairs natural killer cell programming of tumor for lysis in patients with sarcomas and other solid tumors. Cancer 1992, 70:2192-202.

19. Ichihara F, Kono K, Sekikawa T, Matsumoto Y: Surgical stress induces decreased expression of signal-transducing zeta molecules in T cells. Eur Surg Res 1999, 3 I (2): I 38-46.

20. Bhuyan BK: Kinetics of cell kill by hyperthermia. Cancer Res 1979, 39:2277-2284

21. Fajardo LF, Prionas SD: Endothelial cells and hyperthermia. Int J Hyperthermia 1994, 10:347-53.

22. Fajardo LF, Schreiber AB, Kelly NI, Hahn GM: Thermal sensitivity of endothelial cells. Radiat Res 1985, 103:276-85.

23. Eggermont AM, de Wilt JH, ten Hagen TL: Current uses of isolated limb perfusion in the clinic and a model system for new strategies. Lancet Oncol 2003, 4(7):429-37.

24. Van-Leeuwen GM, Kotte AN, De-Bree J, Van der Koijk JF, Crezee J, Lagendijk J): Accurary of geometrical modelling of heat trans fer from tissue to blood vessels. Phys Med Biol | 997, 42: | 45 |-60.

25. Crezee J, Lagendijk J]: Temperature uniformity during hyperthermia: the impact of large vessels. Phys Med Biol 1992 37: $1321-1337$
26. Jain RK, Ward-Hartley K: Tumor blood flow-Characterisation, modi-fications, and role in hyperthermia. Trans Sonics Ultrasonics 1984, 31:504.

27. Dudar TE, Jain RK: Differential response of normal and tumor microcirculation to hyperthermia. Cancer Research 1984, 44:605-6I2

28. Lyons JC, Song CW: Killing of hypoxic cells by lowering the intracellular $\mathrm{pH}$ in combination with hyperthermia. Radiation research 1995, |41:216-218.

29. Mondovi B, Strom R, Rotilio G, Agro AF, Cavaliere R, Fanelli AR: The biochemical mechanism of selectiv heat sensitivity of cancer cells. I. studies on cellular respiration. Europ J Cancer 1969 , 5:129-136.

30. Vrouenraets BC, Kroon BB, van de Merwe SA, Klaase JM, Broekmeyer-Reurink MP, van Slooten GW, Nieweg OE, van der Zee J, van Dongen JA: Physiological implications of hyperbaric oxygen tensions in isolated limb perfusion using melphalan: a pilot study. Eur Surg Res 1996, 28(3):235-44.

31. Koutcher JA, Barnett D, Kornblith B, Cowburn D, Brady TJ, Gerweck $\mathrm{L}$ : Relationship of changes in $\mathbf{p H}$ and energy status to hypoxic cell fraction and hyperthermia sensitivity. Int J Radiat Oncol Biol Phys 1990, 18:|429-1435

\section{Pre-publication history}

The pre-publication history for this paper can be accessed here:

http://www.biomedcentral.com/1471-2407/4/53/prepub

Publish with BioMed Central and every scientist can read your work free of charge

"BioMed Central will be the most significant development for disseminating the results of biomedical research in our lifetime. "

Sir Paul Nurse, Cancer Research UK

Your research papers will be:

- available free of charge to the entire biomedical community

- peer reviewed and published immediately upon acceptance

- cited in PubMed and archived on PubMed Central

- yours - you keep the copyright 